\title{
Função Quadrática: Linguagem Matemática E A Representação De Um Pensamento
}

\author{
Quadratic Function: Mathematical Language And The Representation \\ Of A Thought
}

\author{
Afrânio Austregésilo Thiel * \\ Instituto Federal Catarinense - IFC \\ Thiago Henrique das Neves Barbosa ** \\ Instituto Federal Catarinense - IFC \\ Méricles Thadeu Moretti $* * *$ \\ Universidade Federal de Santa Catarina - UFSC
}

\begin{abstract}
Resumo
Este texto tem por objetivo promover uma reflexão mais profunda sobre o ensino e aprendizagem de 'função quadrática', ou seja, quais são os registros de representação elaborados pelos alunos e qual a sua compreensão dos elementos pertinentes ao tema. Inicialmente destacam-se algumas noções sobre a representação de um pensamento e em seguida faz-se a análise de questões elaboradas e aplicadas em duas turmas do $1^{\circ}$. Ano do Curso Técnico em Agropecuária Integrado ao Ensino Médio (52 alunos), do Instituto Federal Catarinense - Campus Camboriú. A pesquisa realizada reaviva a necessidade de que todo professor deve observar durante o processo de ensino e aprendizagem as dificuldades e o avanço cognitivo quanto às práticas matemáticas realizadas pelos estudantes. Na experiência, ficou evidente a dificuldade que os alunos têm para efetuar o tratamento e converter registros na linguagem natural, algébrica e gráfica. O que acontece, na verdade, é que a compreensão dos estudantes fica limitada à forma de representação que eles conhecem e reproduzem.
\end{abstract}

Palavras-chave: Matemática; Função quadrática; Ensino e aprendizagem

\begin{abstract}
This text aims to promote a deeper reflection on the teaching and learning of 'quadratic function', that is, what are the records of representation elaborated by the students and what their understanding of the elements pertinent to the theme. Some notions about the representation of a thought are initially emphasized, and then the analysis of questions elaborated and applied in two classes of the 1st. Year of the Technical Course in Agriculture Integrated to High School (52 students), Catarinense Federal Institute in Camboriú city. The research revives the need for every teacher to observe during the teaching and learning process the difficulties and cognitive advance regarding the mathematical practices performed by the students. In the experience, it was evident the difficulty that the students have to carry out the treatment and to convert records in the natural, algebraic and graphic language. What happens, in fact, is that students' understanding is limited to the form of representation they know and reproduce.
\end{abstract}

Keywords: Mathematics; Quadratic function; Teaching and learning

\footnotetext{
* Doutor em Educação Científica e Tecnológica (UFSC). Professor aposentado do IFC, Camboriú, Santa Catarina, Brasil. E-mail: afranio.thiel@yahoo.com.

** Mestre em Ensino Ciência e Tecnologia (UTFPR). Professor do IFC, Camboriú, Santa Catarina, Brasil. E-mail: thiago.barbosa@ifc.edu.br.

*** Doutorado em Didática da Matemática (UNISTRA). Professor da UFSC, Florianópolis, Santa Catarina, Brasil. E-mail: mthmoretti@gmail.com.
} 


\section{Preliminares}

Quando se reflete sobre o ensino da matemática na educação básica, somos levados a concordar que o professor além de conhecer esta disciplina, deve contextualizar o saber matemático para ensiná-lo. A aprendizagem envolve a apropriação da vivência do ensinaraprender pelo indivíduo, por meio da experiência social e histórica, dos conhecimentos e modos de ação.

É necessário variar métodos e estratégias para que os estudantes compreendam e assimilem as noções de conteúdos associando a linguagem matemática e, sempre que possível, trabalhar um tema integrando disciplinas com a intenção de que o conhecimento seja global e tenha significado e significância para os alunos.

A LDB, por meio dos PCNs, destaca como características inerentes à atividade docente:

[...] comprometer-se com o sucesso da aprendizagem dos alunos; assumir e saber lidar com a diversidade existente entre eles; incentivar atividades de enriquecimento cultural; desenvolver práticas investigativas; elaborar e executar projetos para desenvolver conteúdos curriculares; utilizar novas metodologias, estratégias e materiais de apoio; desenvolver hábitos de colaboração e trabalho em equipe. (BRASIL, 2001, p. 3).

Segundo Duval (1995 apud THIEL, 2013, p. 50), não há conhecimento matemático que possa ser mobilizado por um aluno sem o auxílio de uma representação ${ }^{1}$. A Figura 1 destaca as três aproximações para a noção de representação de um pensamento, sendo elas: representações subjetiva e mental; representações internas ou computacionais; e representações externas ou semióticas.

1 Entende-se por representação a reunião de um ‘significado' que permite a evolução de um 'significante' previsto por um pensamento. Significado diz respeito ao conceito, ou seja, a ideia na qual a palavra se refere. E o Significante aborda o conceito acústico de um vocábulo, algo captado por nossos ouvidos e registrado pelo cérebro, independente de compreendermos a língua em questão. (SAUSSURE, 1996). 


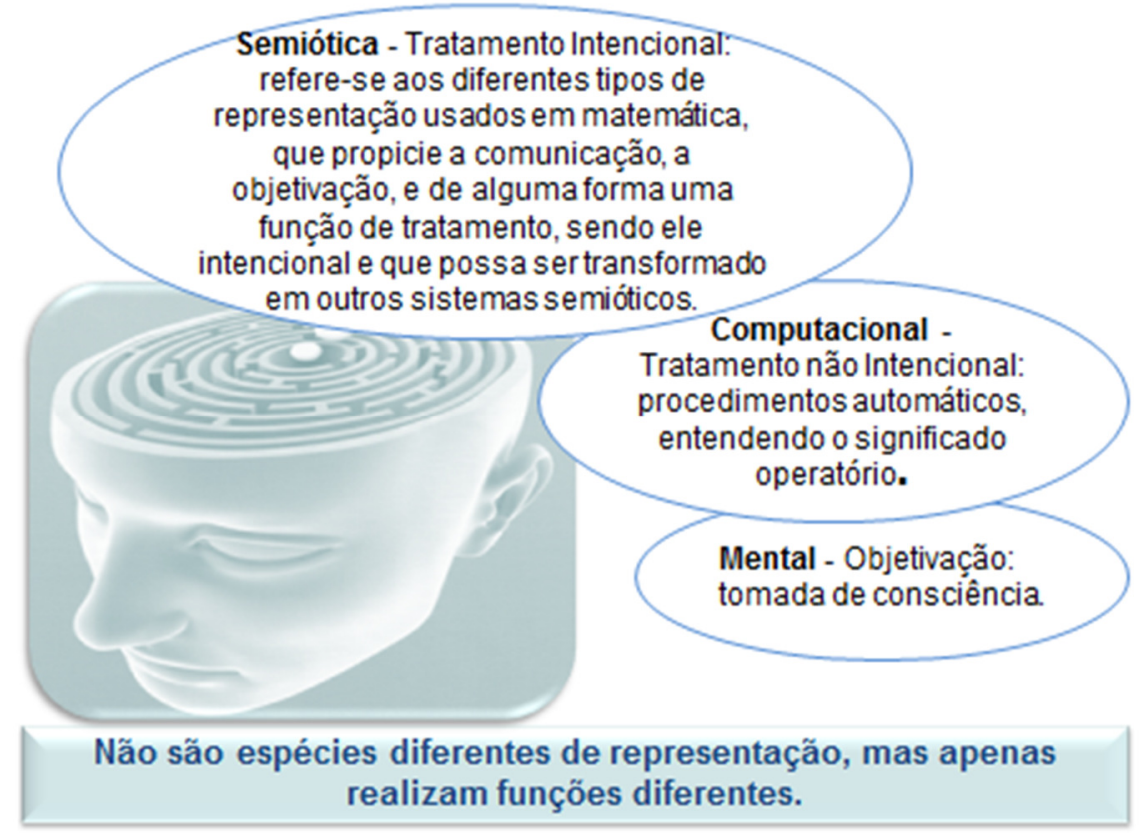

Figura 1 - Noção da representação de um pensamento Fonte: Elaborado pelos autores.

De um modo geral, as representações são divididas em internas e externas, não sendo consensual e livre de conflitos entre alguns filósofos e mesmo psicólogos cognitivistas. As representações internas são aquelas que criamos em nossas mentes, as quais descrevem a cognição dos indivíduos e por isso são conhecidas ainda como representações mentais.

Descreve Colombo (2008, p. 20) que,

No contexto da aprendizagem escolar, as representações mentais podem ser traduzidas como as diversas respostas dos alunos frente às atividades propostas. Já, as representações externas ou semióticas, por sua vez, são aquelas constituídas por sistemas de signos que possuem regras próprias de significação e funcionamento, inventadas pelo homem para mediar as relações com os conhecimentos e as coisas do mundo.

Font, Godino e D’Amore (2004) destacam que para Wittgenstein (1953) e Duval (1993), as representações semióticas seriam meros instrumentos com os quais se exterioriza nossas representações mentais para fins de comunicação, ou seja, para torná-las acessíveis a outras pessoas. Mais que isso, as representações semióticas são essenciais para a atividade cognitiva do pensamento.

Para o pesquisador Raymond Duval (1995) "não há noésis sem semiósis, é a semiósis que determina as condições de possibilidade e de exercício da noésis". O pesquisador afirma que noésis refere-se mais à mobilização do entendimento, ou ainda, à inteligência no sentido da matemática. E, semiósis: representa também o 'signo' ou 'sinal'. 
Cabe destacar que o desenvolvimento do funcionamento do pensamento humano, pressupõe que o sujeito para aprender um conceito precisa fazer distinção entre a representação de um objeto matemático e ele próprio, tendo acesso a este conceito por meio das representações. Daí o papel essencial da atribuição de significados às representações de um conceito no processo de ensino e aprendizagem do mesmo.

Esse 'objeto' a ser representado, poderá ser algo perceptível, concreto (uma coisa material) ou abstrato (uma entidade mental e/ou imaginária).

Segundo Duval (1995) o funcionamento cognitivo do pensamento humano se revela inseparável da existência de uma diversidade de registros semióticos de representação, e não somente para fins de comunicação. Merece destaque que as representações semióticas apresentam dois aspectos: sua forma (o representante) e o seu conteúdo (o representado). Logo, ocorre uma interação entre a apreensão, ou a produção de uma representação semiótica, e a apreensão conceitual de um objeto.

Thiel (2013, p. 40) registra que podem ser encontrados no campo da matemática, dentre vários exemplos que existem, a ideia de signos diferentes evocando diferentes sentidos de um mesmo objeto matemático. Apresenta-se no Quadro 1 o exemplo de Moretti (2002) considerando as representações de uma mesma parábola:

\begin{tabular}{|l|l|}
\hline Representação & $\begin{array}{l}\text { Segundo Moretti (2002), cada uma dessas representações possui, em sua } \\
\text { integridade, as mesmas informações do objeto matemático em referência. Todavia, } \\
\text { do ponto de vista cognitivo, um determinado tipo de informação sobressai mais em } \\
\text { uma do que em outra forma. Observe: }\end{array}$ \\
\hline (a) $\mathrm{y}=\mathrm{x}^{2}-4 \mathrm{x}+3$ & (a) a ideia mental da curva aberta (parábola) com concavidade para cima. \\
\hline (b) $\mathrm{y}+1=(\mathrm{x}-2)^{2}$ & (b) as coordenadas do vértice da parábola. \\
\hline $\begin{array}{l}\text { (c) y }=(\mathrm{x}-3)(\mathrm{x}-1) \\
\text { no plano cartesiano. }\end{array}$ & $\begin{array}{l}\text { (c) com clareza as raízes. } \\
\text { muitas vezes é bastante adequado à interpretação, se for o caso, do fenômeno } \\
\text { representado. Nesta mesma forma, no entanto, não temos com precisão, por } \\
\text { exemplo, o valor de y }(\sqrt{2}) .\end{array}$ \\
\hline
\end{tabular}

Quadro 1 - Representação de signos diferentes do objeto matemático 'parábola'

Fonte: Adaptado de Moretti (2002, p. 347).

Argumenta Thiel (2013, p. 44) que na compreensão de Duval (2004),

O processo de negociação dos 'registros de representação semiótica' entre professor e aluno, na análise do desenvolvimento dos conhecimentos e da aprendizagem, suscitam três fenômenos estreitamente relacionados: o da diversidade de registros, possuindo em cada um, questões específicas de aprendizagem; o da 
diferenciação entre representante (forma) e representado (conteúdo) e o da coordenação para diferentes tipos de registros disponíveis, para os quais o sujeito necessita, não só para se ter conhecimento das regras de correspondência entre eles, mas dentro do possível, ter a compreensão de congruência e não congruência.

Percebemos assim, que o sentido de uma representação relaciona-se diretamente ao modo como essa representação é apresentada, ou seja, com o registro de representação semiótica escolhido. Nestes termos, seriam os sentidos diferentes revelados pelo uso de representações distintas que forneceriam a possibilidade de tratamentos diferenciados aos objetos de conhecimento.

Quando tomamos como referência o tema função polinomial do segundo grau, pode-se observar a dificuldade que os estudantes têm na compreensão dos elementos que fazem parte de uma parábola. Como dica inicial de experiências sugere-se que se faça uma abordagem do conteúdo partindo de uma ilustração contextualizando uma função quadrática e seu respectivo esboço contendo os elementos. Sinaliza-se que por meio de aulas dialogadas e as reflexões feitas durante as aulas, pode ser um fator facilitador de aprendizagem sobre o tema.

Imagine um rosto de um(a) homem ou mulher: nele podemos observar duas parábolas (uma com concavidade para cima e outra com concavidade para baixo); o eixo de simetria em relação ao eixo vertical que passa pelo vértice; os vértices (ponto de máximo 'ponto crítico de subida: pico, cume' e ponto de mínimo 'ponto crítico de descida: declínio, depressão'); o valor máximo ou o valor mínimo; as raízes da função que determinará onde a parábola cruzará o eixo 0x; a tendência da curva (função crescente e função decrescente); a variação no eixo x (domínio) e a variação no eixo y (imagem) da função.

A primeira indagação que deve ser feita é por que e para que se planeja uma aula? Planejam-se as aulas para organizar todos os passos e encaminhamentos a serem seguidos com vistas à apreensão de um conhecimento. A segunda, para que nível de escolaridade deve-se ensinar determinado conteúdo? E, finalmente, por que ensiná-lo?

É evidente que as orientações repassadas pelo professor são para que o estudante possa ter a possibilidade de uma reflexão acerca de um tema, podendo até ocorrer o envolvimento entre áreas do conhecimento. Mas de que forma isso ocorre? Pode-se afirmar que ocorre quando se apresenta situações reais e ou simuladas, dentro do seu contexto social, e, que despertem a atenção e interesse por parte do estudante.

Duval (1993) corrobora afirmando que a conceitualização acontece quando o sujeito é capaz de mobilizar instantaneamente, um registro de representação semiótica do objeto 
matemático, escolhido entre os muitos que se apresenta, de modo a favorecer a resolução de um dado problema da forma mais econômica possível.

Também é manifesto que a existência de muitos registros possibilita a realização de tratamentos de forma mais econômica - eficaz. A economia em um tratamento está muito vinculada a aproximação com a língua natural e, principalmente, as formas mais simples e econômicas aos procedimentos adotados por cada sujeito.

Para uma melhor compreensão destacamos no Quadro 2, pontos importantes no que diz respeito à representação semiótica e sua estrutura básica.

\begin{tabular}{|c|c|}
\hline \multicolumn{1}{|c|}{ REPRESENTAÇÃO SEMIÓTICA } \\
\hline$\checkmark \quad$ SEMIÓSIS (Representaçães) \\
$\checkmark \quad$ Formação - Segundo Duval (2012), a formação de uma representação identificável é como a \\
representação de um registro dado, podendo ser: enunciado de uma frase, elaboração de um esquema, \\
expressão de uma fórmula, desenho de uma figura, dentre outros. Desta maneira, pode ser comparada \\
a realização de uma tarefa de descrição, respeitando regras gramaticais para as línguas naturais, regras \\
de formação num sistema formal, etc. \\
$\checkmark \quad$ Tratamento - É uma transformação interna de um registro. Para Duval (2012), do ponto de vista \\
“pedagógico”, devemos algumas vezes procurar o melhor registro de representação a ser utilizado, \\
para que os alunos possam compreender um objeto matemático. Ex.: resolver uma equação ou um \\
sistema de equações; completar uma figura segundo critérios de conexidade e de simetria; efetuar um \\
cálculo ficando no mesmo sistema de escrita ou de representação dos números. \\
$\checkmark \quad$ Conversão - É a transformação de um registro em um outro registro, conservando a totalidade ou uma \\
parte do objeto matemático em questão. Não podemos confundir a conversão com a ação de codificar \\
e com a interpretação, apesar de serem operações muito próximas. A ação de codificar seria a \\
transcrição de uma representação em um outro sistema semiótico diferente do anterior e a interpretação \\
seria a modificação do contexto ou a alteração do quadro teórico. Logo, a 'tradução' é a conversão de \\
uma representação linguística dentro de uma linguagem dada por uma representação em uma outra \\
língua ou de outro tipo de linguagem. E, a 'descrição' é a conversão de uma representação não verbal \\
(esquema, figura, gráfico) em uma representação linguística.
\end{tabular}

Quadro 2 - A representação semiótica e sua estrutura básica

Fonte: Organizado pelos autores.

Em nosso cotidiano, sem perceber, realizamos quase que plenamente todo esse processo de representação semiótica e sua estrutura básica.

\section{A Experiência Prática}

A experiência foi realizada em junho de 2016 tendo a participação de duas turmas do 1. Ano do Curso Técnico em Agropecuária Integrado ao Ensino Médio (52 alunos), do Instituto Federal Catarinense - Campus Camboriú, envolvendo quatro aulas, sendo uma para a socialização dos elementos constituintes de uma função quadrática e três aulas para as atividades propostas. A escolha dessas turmas ocorreu por serem alunos oriundos de escolas 
públicas da região (egressos do 9. Ano do Ensino Fundamental), com conhecimentos básicos sobre resolução de equações do 2. Grau e elaboração de um gráfico. Outro fator relevante é a constatação do alto índice de retenção dos alunos na disciplina de matemática no curso em questão do ano mencionado.

As atividades foram desenvolvidas e os resultados registrados por meio de percentuais de acertos e de erros. Descreve-se também de que forma o estudante assimilou este conhecimento, ou seja, como ele compreende e expressa suas respostas com respeito aos elementos que integram o tema. A posteriori dessas atividades, e que não fazem parte do presente trabalho, foram abordadas as aplicações (situações do cotidiano) ligadas ao tema.

A função polinomial do $2^{\circ}$ Grau (função quadrática) tem como expressão geral $f(x)=$ $a x^{2}+b x+c$, com $a, b, c$ pertencente ao conjunto dos reais e $a \neq 0$.

Inicia-se apresentando situações onde se destaca a imagem de uma parábola. Em seguida faz-se a socialização da face de uma pessoa mostrando a similaridade com o gráfico (a parábola) de uma função quadrática dando as sugestões iniciais para uma compreensão inicial dos pontos importantes no estudo desta função, conforme é ilustrado na Figura 1.

Neste momento o estudante é estimulado a realizar uma representação do pensamento computacional e mental comparando a face de um ser humano com a função quadrática. Este momento aconteceu de forma socializada, ou seja, os autores destacaram na ilustração da face (Figura 2), as características básicas presentes numa função quadrática.

Concluída esta etapa passa-se para as situações problemas com imagens gráficas e expressões algébricas, envolvidas por diferentes registros de representação ligadas ao objeto de estudo. 


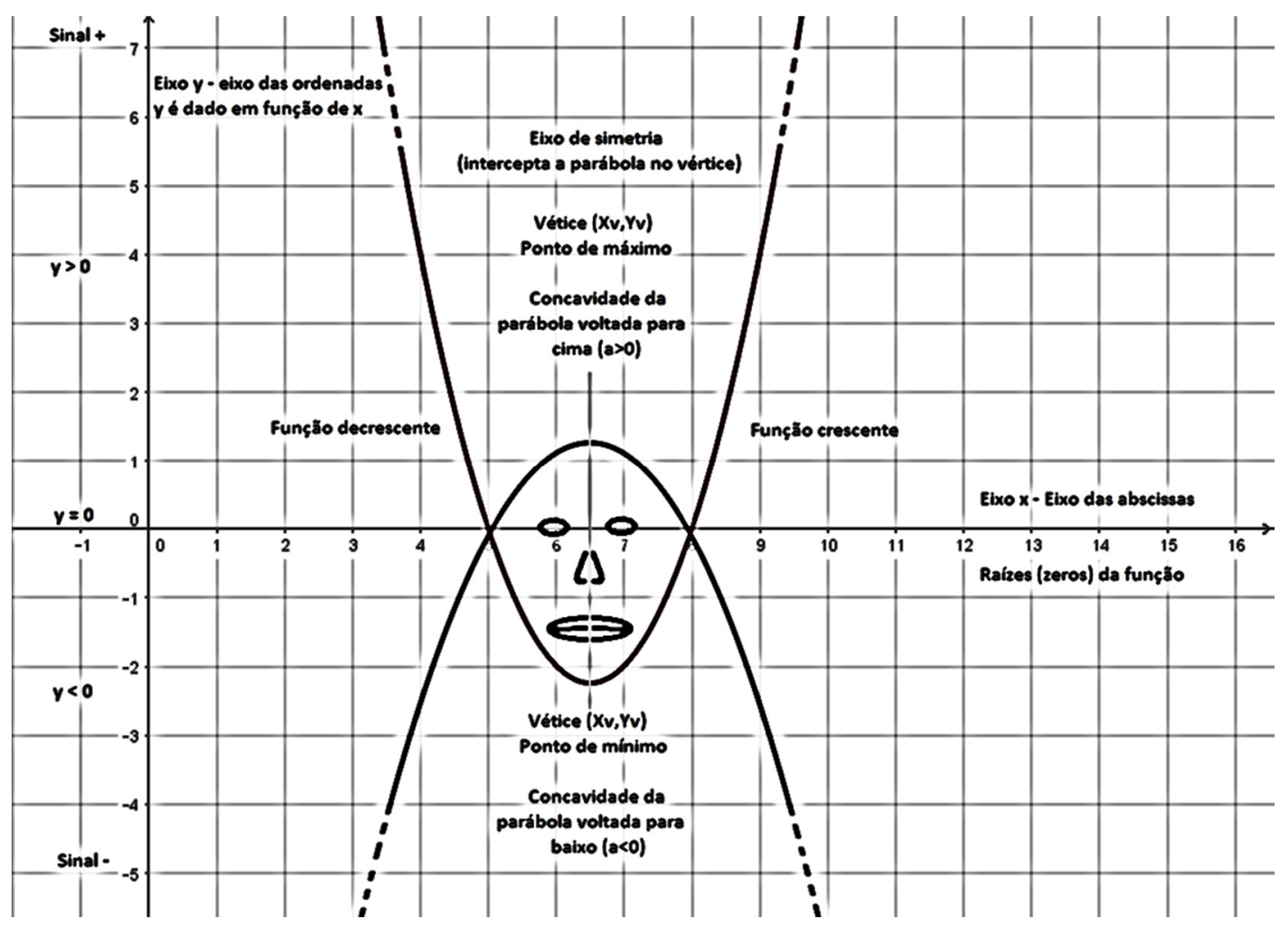

Figura 2 - Comparação da face de um ser humano com a função quadrática Fonte: elaborado pelos autores.

O segundo passo foi envolver situações do cotidiano destacando as características de uma função quadrática $f(x)=a x^{2}+b x+c$, levando em consideração os registros de representação semiótica pertinentes:

a) Plano cartesiano ortogonal: cada eixo é subdividido em segmentos de mesma medida (unidade); os eixos desenhados na posição horizontal e vertical são denominados de eixo da abscissa (denotado por 0x) e eixo das ordenadas (denotado por 0y).

b) A concavidade da parábola (para cima ou para baixo - observar o coeficiente a);

c) Encontrar as raízes da função que determinará onde a parábola cruzará o eixo 0x (da abscissa) - conhecido em linguagem matemática, como os zeros da função descrevendo o(s) ponto(s) se existir;

d) As coordenadas do vértice;

e) Indicar a ordenada em que o gráfico intercepta o eixo 0y (da ordenada) - observar o coeficiente c;

f) O esboço do gráfico indicando o eixo de simetria em relação ao eixo vertical que passa pelo vértice;

g) Definir o valor máximo ou o valor mínimo;

h) Dar a variação no eixo x (domínio) e a variação no eixo y (imagem) da função; 
i) Indicar o intervalo em que a função é crescente ou decrescente;

j) Fazer uma leitura panorâmica geral da situação, ou seja, o estudo dos sinais (para que valores da variável $\mathrm{x}$ se obtém: $\mathrm{y}<0, \mathrm{y}=0$ e y $>0$.

\section{A Discussão}

Após as reflexões das características de uma função quadrática apresentamos algumas imagens gráficas (Figuras 3 a 5) solicitando aos estudantes que determinassem alguns itens, visualizando a imagem.

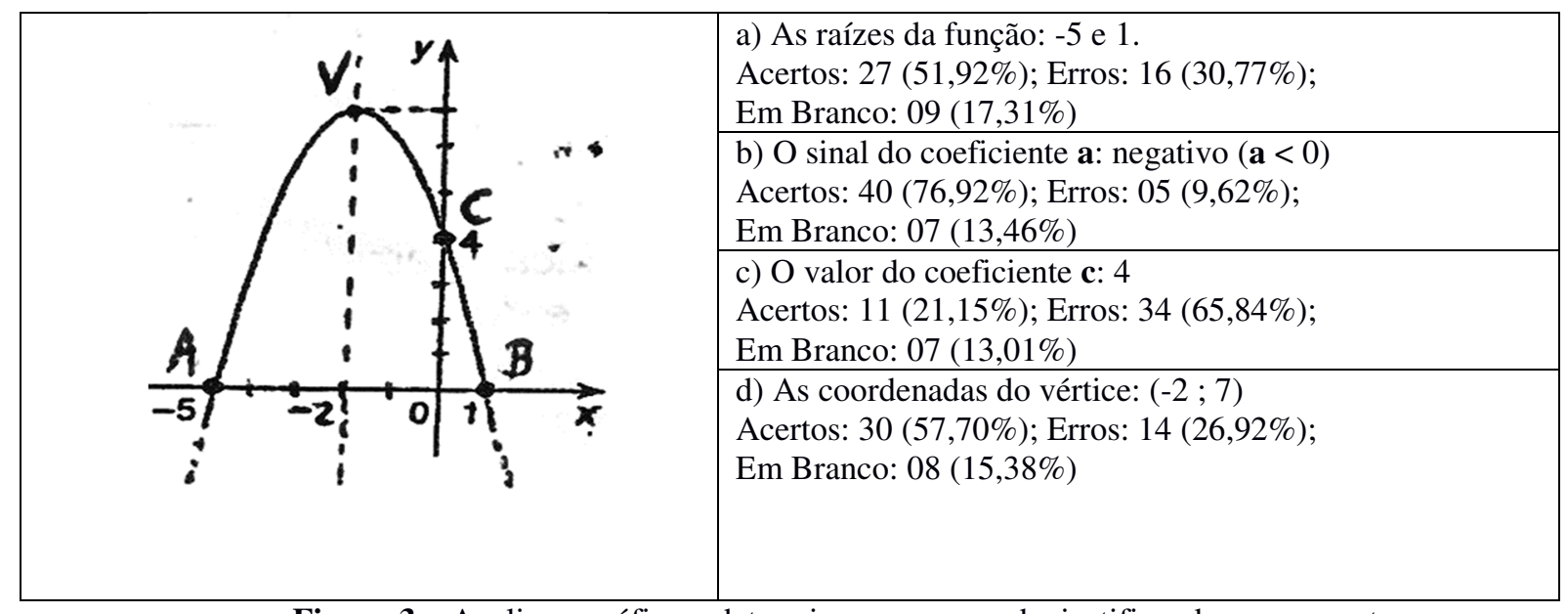

Figura 3 - Analise o gráfico e determine o que se pede, justificando sua resposta

Fonte: Documentos dos autores.

Comentários: a) Sobre as raízes da função - percebeu-se que 51\% de acertos. Duas questões foram levantadas pelos alunos: $1^{\circ}$ ) a dificuldade consiste para associar na linguagem natural os termos 'raízes' ou 'zeros da função' como sendo os valores em que o gráfico intercepta o eixo x. $2^{\circ}$ ) quando é preciso determinar as coordenadas dos pontos em que o gráfico toca (cruza) o eixo x, a dúvida que paira é qual será o valor de y. Eles conseguiram localizar o valor correspondente na abscissa (horizontal) traçando uma reta auxiliar, paralela ao eixo vertical. Entretanto, a dúvida para localizar o valor correspondente na ordenada (vertical) traçando uma reta auxiliar, paralela ao eixo horizontal. b) $\mathrm{O}$ sinal do coeficiente $\mathbf{a}-$ houve $76 \%$ de acertos; constatou-se que a confusão dos demais alunos foi em identificar a relação entre o sinal '+' e '-', e o símbolo de desigualdade ' $>0$ ' e ' $<0$ ', contextualizando assim a forma da curvatura da parábola 'concavidade para cima' e 'concavidade para baixo'. c) $\underline{\mathrm{O} \text { valor do }}$

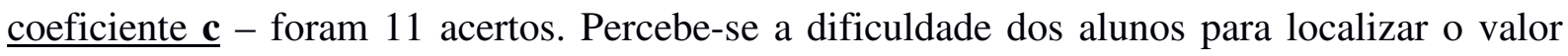
correspondente na abscissa (horizontal) traçando uma reta auxiliar, paralela ao eixo vertical. d) As coordenadas do vértice - houve $57 \%$ de acertos, e a fragilidade do restante dos alunos 
consiste na compreensão de que cada ponto do plano cartesiano é identificado por um par de números chamados de coordenadas, determinando uma posição sobre a superfície. Nesse caso, um dos valores determina a distância da origem até a projeção ortogonal do ponto no eixo das abscissas (medida horizontalmente) e o outro, a distância da origem até a projeção ortogonal do no eixo das ordenadas (medida verticalmente). E, para obter um ponto $\mathrm{P}$ qualquer, basta traçar as perpendiculares ao eixo x e y. Nas situações matemáticas práticas, cada eixo é nominado e enumerado observando a grandeza correspondente, acompanhada por sua respectiva unidade de medida.

Na imagem da Figura 4 foi solicitado que o estudante observasse o gráfico da parábola e em seguida apontasse as afirmações com $(V)$ para verdadeiro e $(F)$ para falso.

\begin{tabular}{|c|c|}
\hline 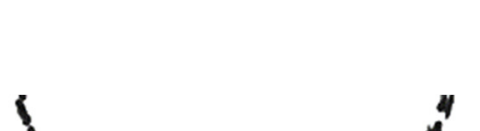 & $\begin{array}{l}\text { a) (F) O vértice é um ponto máximo. } \\
\text { Acertos: } 24(46,15 \%) \text {; Erros: } 21(40,39 \%) \text {; } \\
\text { Em Branco: } 07(13,46 \%)\end{array}$ \\
\hline & $\begin{array}{l}\text { b) (V) O vértice é um ponto mínimo. } \\
\text { Acertos: } 27(51,92 \%) \text {; Erros: } 17(32,69 \%) \\
\text { Em Branco: } 08(15,39 \%)\end{array}$ \\
\hline & $\begin{array}{l}\text { c) (V) O gráfico não tem zeros da função (raízes). } \\
\text { Acertos: } 29(55,77 \%) \text {; Erros: } 15(28,84 \%) \text {; } \\
\text { Em Branco: } 08(15,39 \%)\end{array}$ \\
\hline & $\begin{array}{l}\text { d) (F) Sobre coeficientes: a }>0 \text { e } \mathbf{c}<0 \text {. } \\
\text { Acertos: } 26(50,00 \%) ; \text { Erros: } 19(36,54 \%) \\
\text { Em Branco: } 07(13,46 \%)\end{array}$ \\
\hline 0 & \\
\hline$f(x)=a x^{2}+b x+c$ & $\begin{array}{l}\text { e) (V) Sobre coeficientes: a > } 0 \text { e c > } 0 \text {. } \\
\text { Acertos: } 34(65,39 \%) \text {; Erros: } 14(26,92 \%) \text {; } \\
\text { Em Branco: } 04(07,69 \%)\end{array}$ \\
\hline
\end{tabular}

Figura 4 - Função quadrática: o gráfico da parábola, sua concavidade e seu vértice Fonte: Documentos dos autores.

Comentários: a) O vértice é um ponto máximo - só 24 (46,1\%) e no item b) O vértice é um ponto mínimo ocorreu $27(51,9 \%)$ acertos dos 52 alunos pesquisados. Os estudantes arguiram que não fizeram a relação 'máximo ou mínimo' como sendo o 'maior ou menor' valor de y, tomando como base o valor do eixo x (eixo de simetria - que divide a parábola em duas partes iguais); alguns lembraram o valor supremo de y, referindo-se ao queixo do seu rosto. E, os que assinalaram em branco, não compreenderam o enunciado do texto. No item c) $\mathrm{O}$ gráfico não tem zeros da função (raízes) - $29(55,7 \%)$ acertaram a afirmação, reforçando que a dificuldade consiste em associar os termos 'zeros da função' ou 'raízes' com a imagem gráfica (Figura 04). Por fim nos itens d) Sobre os coeficientes: $\mathbf{a}>0$ e $\mathbf{c}<0$ e e) Sobre os coeficientes: a $>0$ e c $>0$, com respectivamente 26 e $34(50,0 \%$ e $65,3 \%)$ de acertos, o comentário dos 
alunos diante dos 'erros e em branco' ocorre: $1^{\circ}$ ) não associação da expressão do termo geral da função do $2^{\circ}$ Grau com a característica do gráfico (sinal do coeficiente a); $2^{\circ}$ ) confusão em identificar a relação entre o sinal '+' e '-', e o símbolo de desigualdade ' $>0$ ' e ‘ $<0$ ' tanto para o coeficiente a, quanto para o termo independente c. $3^{\circ}$ ) compreensão de que o valor do termo c, indica sempre onde o gráfico intercepta o eixo y (da ordenada), sendo possível observar no gráfico que intercepta esse eixo num valor positivo (+), maior que zero $(>0)$. $4^{\circ}$ ) Dez alunos esclareceram que chegaram até a substituir $\mathrm{x}=0$, porém por não terem $\mathrm{o}$ valor dos termos $\mathbf{a}, \mathbf{b}$ e c não conseguiram chegar a um dado numérico, tão pouco percebendo que na situação, o fundamental estava em perceber no eixo y onde estava localizado o ponto (se no sentido ' + ' ou '-’).

Dando sequência foi apresentada a imagem de uma caricatura (Figura 5), fazendo uso de uma parábola comparada ao rosto de uma pessoa.

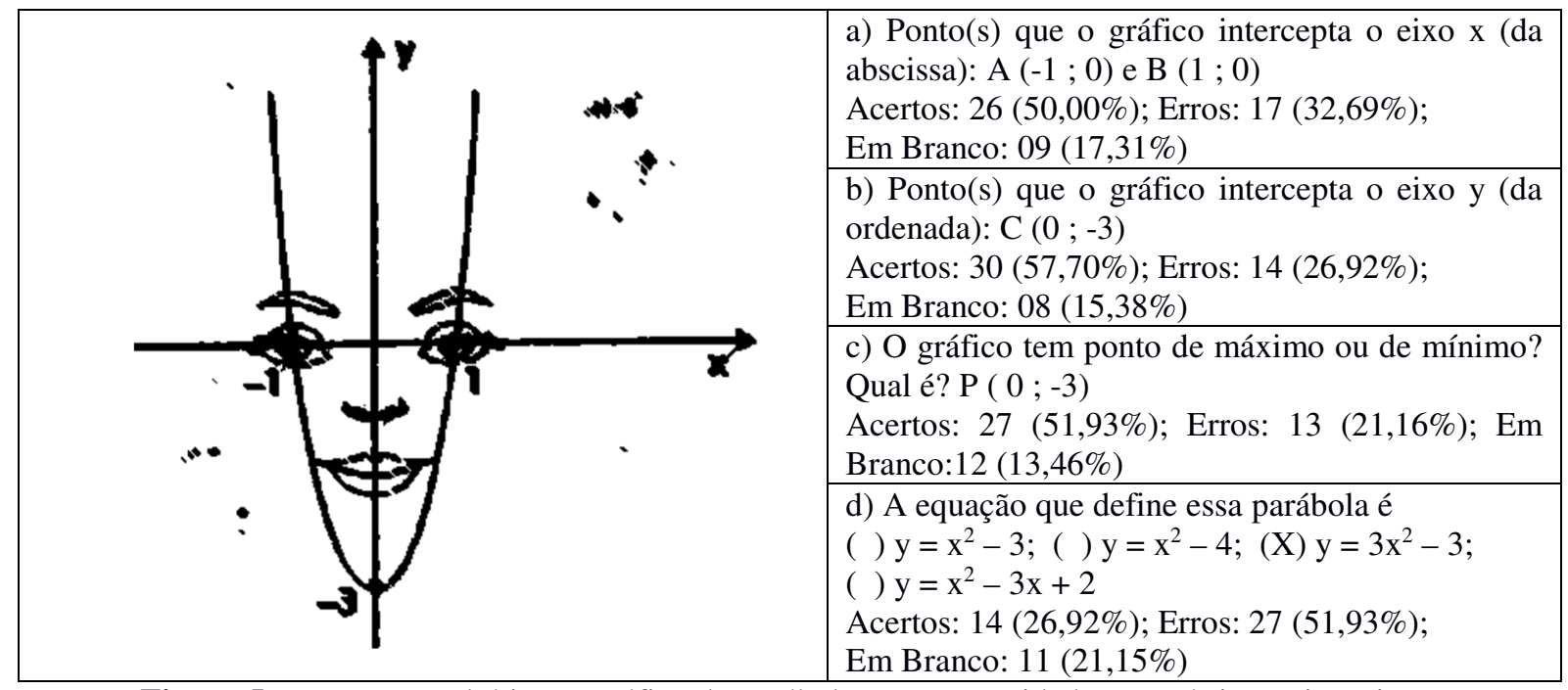

Figura 5 - Função quadrática: o gráfico da parábola, sua concavidade, seu vértice e simetria Fonte: Documentos dos autores.

Comentários: $\mathrm{O}$ aporte da Figura 5 teve como intenção que os estudantes vivenciassem as conversões entre a linguagem na forma gráfica para a forma algébrica e vice-versa. Os autores entendem ser a operação cognitiva de conversão dos registros que constitui uma condição de acesso à compreensão em matemática. O desafio nessa etapa, segundo Duval (2004, p. 89) são as três funções meta-discursivas (comunicação, tratamento e objetivação). Os dois primeiros itens pedem respectivamente as coordenadas cartesianas dos pontos interceptados pela parábola no 'eixo x' e 'eixo y'. O momento exigia a habilidade para fazer a correspondência entre o ponto de encontro, dando as coordenadas e/ou localização do ponto num dos quadrantes e/ou eixos. Observa-se que o fator limitante deles está em abstrair a ideia de que quando o ponto aparece num dos eixos o outro tem valor nulo, pois quase sempre não 
utilizam o aporte da intersecção das retas auxiliares que permitem identificar o valor em cada eixo e a localização do ponto $\mathrm{P}(\mathrm{x} ; \mathrm{y})$. c) $\underline{\mathrm{O} \text { gráfico tem ponto de máximo ou de mínimo? Qual }}$ é? $27(51,9 \%)$ dos alunos acertaram, e o restante registrou que visualizaram onde se situava o vértice, porém a dificuldade se encontrava nos termos 'máximo e mínimo' e dar a coordenada do vértice quando ele está situado sobre um dos eixos. Sobre o item d) A equação que define essa parábola $-38(73,1 \%)$ dos 52 alunos não conseguiram definir a expressão algébrica. Cabe duas observações: $1^{\circ}$ ) Grande parte dos estudantes teve dificuldade em substituir o valor de uma variável (no caso a de ' $x$ ') nas expressões dadas, além das operações dos sinais e tabuada. Registrasse que antes da aplicação destas atividades foi socializado alguns exemplos com as turmas; $2^{\circ}$ ) Outros não, não definindo corretamente as coordenadas do ponto $\mathrm{P}(\mathrm{x} ; \mathrm{y})$, substituíam um valor aleatório, não chegando a um resultado plausível $\left(\mathrm{y}=\mathrm{ax} \mathrm{x}^{2}+\mathrm{bx}+\mathrm{c}\right)$.

Finalizando o rol de atividades foi proposta na forma algébrica a expressão $f(x)=x^{2}$ $5 \mathrm{x}+4$, sendo solicitado aos alunos que determinassem todas as características de uma função quadrática $f(x)=a x^{2}+b x+c$, dos itens ('a' ao 'j'). No Quadro 3 expomos cada item acompanhado dos resultados seguido de análise.

Nesta etapa da pesquisa os autores entendem que não basta o estudante apenas resolver questões isoladas, mas para saber se houve compreensão do assunto é necessário que o aluno realize a análise completa interligando todos os itens, integrados por meio de uma expressão algébrica apresentada pelos pesquisadores. Percebe-se que os livros didáticos raramente fazem essa associação ligando todos os elementos de uma função quadrática, o que segundo nossa percepção, leva a questionar se houve a compreensão efetiva acerca do tema, sensibilizando o aluno a relacionar o assunto com situações reais do cotidiano.

\begin{tabular}{|c|c|}
\hline $\begin{array}{lll}\text { Função Quadrática } & - & \text { Característica } \\
\mathbf{f}(\mathbf{x})=\mathbf{x}^{\mathbf{2}}-\mathbf{5} \mathbf{x}+\mathbf{4} & & \text { solicitada (item) }\end{array}$ & $\begin{array}{l}\text { Resolução de cada item, com a porcentagem de (acertos, erros, } \\
\text { em branco) dos alunos. }\end{array}$ \\
\hline $\begin{array}{l}\text { a) A concavidade da parábola (para cima ou } \\
\text { para baixo). }\end{array}$ & $\begin{array}{l}\text { A concavidade é voltada para cima, pois a>0. Neste caso a }= \\
1 \\
\text { Acertos: } 45(86,54 \%) ; \text { Erros: } 04(7,69 \%) ; \\
\text { Em Branco: } 03(5,77 \%)\end{array}$ \\
\hline $\begin{array}{l}\text { b) Encontrar as raízes da função que } \\
\text { determinará onde a parábola cruzará o eixo 0x } \\
\text { (da abscissa), descrevendo o(s) ponto(s) se } \\
\text { existir. }\end{array}$ & $\begin{array}{l}\text { Para encontrar as raízes, basta igualar a função a zero e } \\
\text { resolver a equação do } 2^{\circ} \text { grau. }\end{array}$ \\
\hline
\end{tabular}




\begin{tabular}{|c|c|}
\hline & $\begin{aligned} \mathrm{f}(\mathrm{x})=0 \Rightarrow \mathrm{x}^{2}-5 \mathrm{x}+4=0\left\{\begin{array}{l}\mathrm{a}=1 \\
\mathrm{~b}=-5 \\
\mathrm{c}=4\end{array}\right. \\
\Delta=\mathrm{b}^{2}-4 \mathrm{ac} \\
\Delta=(-5)^{2}-4.1 .4 \\
\Delta=25-16 \Rightarrow \Delta=9 \\
\mathrm{x}=\frac{-\mathrm{b} \pm \sqrt{\Delta}}{2 \mathrm{a}} \\
\mathrm{x}=\frac{-(-5) \pm \sqrt{9}}{2.1} \\
\mathrm{x}=\frac{5 \pm 3}{2}=\left\{\begin{array}{l}\mathrm{x}^{\prime}=4 \\
\mathrm{x}^{\prime \prime}=1\end{array}\right. \\
\mathrm{S}=\{1,4\} \\
\text { Acertos: } 34(65,39 \%) ; \text { Erros: } 14(26,92 \%) ; \\
\text { Em Branco: } 04(7,69 \%)\end{aligned}$ \\
\hline c) As coordenadas do vértice. & $\begin{array}{l}\text { Para achar as coordenadas do vértice usamos: } \\
\qquad \begin{array}{cc}\mathrm{x}_{\mathrm{v}}=-\frac{\mathrm{b}}{2 \mathrm{a}} & \mathrm{y}_{\mathrm{v}}=-\frac{\Delta}{4 \mathrm{a}} \\
\mathrm{x}_{\mathrm{v}}=-\frac{(-5)}{2.1} & \mathrm{y}_{\mathrm{v}}=-\frac{9}{4.1} \\
\mathrm{x}_{\mathrm{v}}=\frac{5}{2}=2,5 & \quad \mathrm{y}_{\mathrm{v}}=-\frac{9}{4}=-2,25 \\
\text { Acertos: } 27(51,92 \%) ; \text { Erros: } 17(32,69 \%) ; \\
\text { Em Branco: } 08(15,39 \%)\end{array}\end{array}$ \\
\hline $\begin{array}{l}\text { d) Indicar a ordenada em que o gráfico } \\
\text { intercepta o eixo 0y (da ordenada) e as } \\
\text { coordenadas do Ponto } \mathrm{P}(\mathrm{x} ; \mathrm{y}) \text {. }\end{array}$ & $\begin{array}{l}\text { Para achar a ordenada do ponto onde a função intercepta o eixo } \\
\text { 0y, basta fazer } \begin{array}{l}f(0) \text {, assim temos: } \\
f(0)=0^{2}-5.0+4 \\
f(0)=4\end{array} \\
\text { Note que a ordenada deste ponto é justamente o coeficiente } \\
\text { "c" } \\
\text { Acertos: } 29(55,78 \%) ; \text { Erros: } 08(15,38 \%) ; \\
\text { Em Branco: } 15(28,84 \%)\end{array}$ \\
\hline $\begin{array}{l}\text { e) } \mathrm{O} \text { esboço do gráfico indicando o eixo de } \\
\text { simetria em relação ao eixo vertical que passa } \\
\text { pelo vértice. (panorâmica da situação } \\
\text { contendo os itens } b, c, d) \text {. }\end{array}$ & 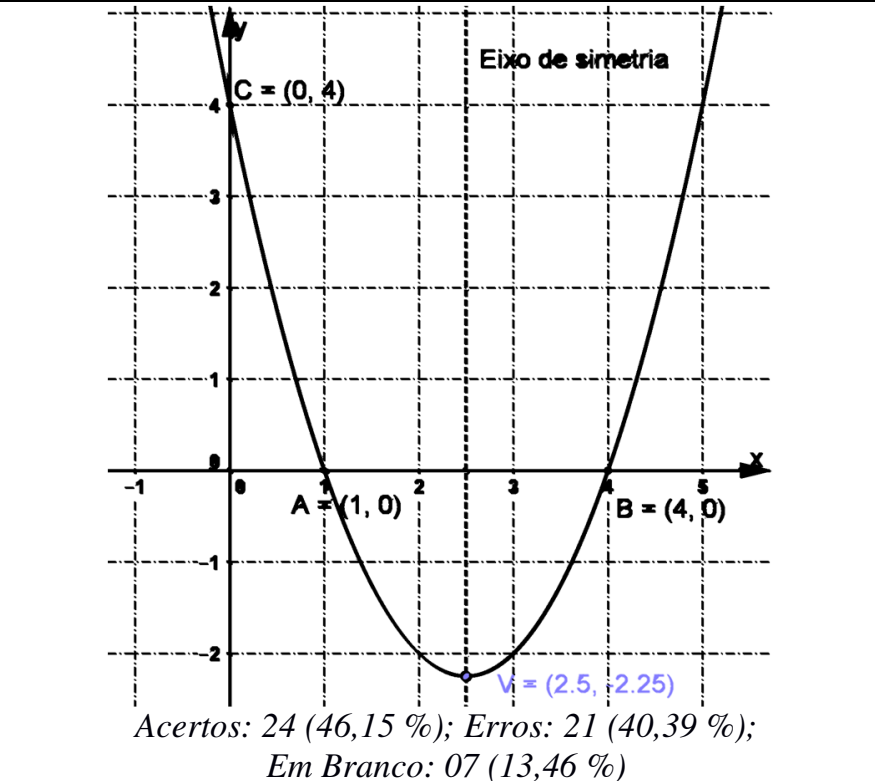 \\
\hline
\end{tabular}




\begin{tabular}{|c|c|}
\hline f) Definir o valor máximo ou o valor mínimo. & $\begin{array}{l}\text { Como a }>0 \text {, há um valor mínimo da função. Em particular, ele } \\
\text { é o y vértice. Portanto: } \\
\qquad \mathrm{y}_{\mathrm{v}}=\mathrm{y}_{\min }=-\frac{9}{4}=-2,25 \\
\text { Acertos: } 14(26,92 \%) ; \text { Erros: } 27(51,93 \%) ; \\
\text { Em Branco: } 11(21,15 \%)\end{array}$ \\
\hline $\begin{array}{l}\text { g) Dar a variação no eixo x (domínio) e a } \\
\text { variação no eixo y (imagem) da função. }\end{array}$ & $\begin{array}{l}\text { O domínio da função corresponde a todos os valores reais. } \\
\text { Note que por se tratar de uma função polinomial, não há } \\
\text { restrições para valores do domínio. No caso da imagem temos } \\
\text { que o valor mínimo da função é }-2,25 \text {. Contudo não há uma } \\
\text { menor cota superior (denominado supremo do conjunto), } \\
\text { assim temos: } \\
\qquad D_{\mathrm{f}}=\mathbb{R} \\
\qquad \mathrm{Im}_{\mathrm{f}}=\{\mathrm{x} \in \mathbb{R} / \mathrm{x} \geq-2,25\} \text { ou } \operatorname{Im}_{\mathrm{f}}=[-2,25 ; \infty[ \\
\text { Acertos: } 07(13,46 \%) ; \text { Erros: } 32(61,54 \%) ; \\
\text { Em Branco: } 13(25,00 \%)\end{array}$ \\
\hline $\begin{array}{l}\text { h) Indicar o intervalo em que a função é } \\
\text { crescente ou decrescente. }\end{array}$ & $\begin{array}{c}\begin{array}{r}]-\infty ; 2,5[\Rightarrow \text { função decrescente. } \\
] 2,5 ; \infty[\Rightarrow \text { função crescente. }\end{array} \\
\text { Acertos: } 11(21,15 \%) ; \text { Erros: } 24(46,16 \%) ; \\
\text { Em Branco: } 17(32,69 \%)\end{array}$ \\
\hline $\begin{array}{l}\text { i) Verifique se os pontos } \mathrm{P}_{1}(-1 ; 10), \mathrm{P}_{2}(2 ;- \\
5) \text {, e } \mathrm{P}_{3}(0 ; 4) \text { pertencem ou não pertencem a } \\
\text { função } \mathrm{f}(\mathrm{x}) \text {. }\end{array}$ & $\begin{array}{l}\text { Vamos analisar cada um dos pontos: } \\
\left.\qquad \begin{array}{l}\mathrm{P}_{1}(-1 ; 10): \\
\mathrm{f}(-1)=(-1)^{2}-5 \cdot(-1)+4 \\
\mathrm{f}(-1)=1+5+4=10 \\
\mathrm{P}_{2}(2 ;-5): \\
\mathrm{f}(2)=2^{2}-5.2+4 \\
\mathrm{f}(2)=4-10+4=-2 \\
\mathrm{P}_{3}(0 ; 4): \\
\mathrm{f}(0)=0^{2}-5.0+4 \\
\mathrm{f}(0)=0-0+4=4\end{array}\right\} \therefore \mathrm{P}_{2} \notin \mathrm{f} \\
\\
\text { Acertos: } 13(25,00 \%) ; \text { Erros: } 29(55,77 \%) ; \\
\text { Em Branco: } 10(19,23 \%)\end{array}$ \\
\hline $\begin{array}{l}\text { j) Fazer uma leitura geral do 'estudo dos } \\
\text { sinais', ou seja, para que valores da variável } \mathrm{x} \\
\text { se obtém: } \mathrm{y}<0, \mathrm{y}=0 \text { e } \mathrm{y}>0 \text {. }\end{array}$ & $\begin{array}{l}\mathrm{x}<1 \text {, isto é, }]-\infty ; 1[\Rightarrow \mathrm{f}(\mathrm{x})>0 \\
\mathrm{x}=1 \Rightarrow \mathrm{f}(\mathrm{x})=0 \\
1<\mathrm{x}<4, \text { isto é, }] 1 ; 4[\Rightarrow \mathrm{f}(\mathrm{x})<0 \\
\mathrm{x}=4 \Rightarrow \mathrm{f}(\mathrm{x})=0 \\
\mathrm{x}>4, \text { isto é, }] 4 ; \infty[\Rightarrow \mathrm{f}(\mathrm{x})>0 \\
\\
\text { Acertos: } 2(3,85 \%) ; \text { Erros: } 18(34,61 \%) ; \\
\text { Em Branco: } 32(61,54 \%)\end{array}$ \\
\hline
\end{tabular}

Quadro 3 - Atividade envolvendo as características básicas de uma função do $2^{\circ} \mathrm{Grau}$ Fonte: Documentos dos autores.

Comentários: os registros dos percentuais de acerto (86\%) do item a, apontam que nesta etapa da experiência houve uma maior acomodação na ideia sobre a forma do gráfico concavidade da parábola para cima (a $>0$ e para baixo a $<0$ ), os erros dos demais alunos aconteceu na confusão em identificar a relação entre o sinal '+' e '-', e o símbolo de desigualdade ' $>0$ ' e ' $<0$ ' tanto para o coeficiente $\mathbf{a}$. 
Já no item b, para determinar a(s) raiz(es) da função percebe-se erros no cálculo para encontrar a raiz e em alguns casos em abstrair a ideia de que quando o ponto aparece num dos eixos o outro tem valor nulo, sendo neste item o ponto $\mathrm{P}(\mathrm{x} ; 0)$; foram registrados Erros: 14 $(26,92 \%)$ e em Branco: 04 (7,69\%).

Sobre o item para determinar as coordenadas do vértice, os 27 (48,08\%) estudantes que erraram ou deixaram em branco confirmaram que embora tenham sido realizadas discussões em sala, não perceberam que quando se tem duas raízes, o ponto médio entre elas é o valor do $\mathrm{x}_{\mathrm{v}}$. Outros esqueceram da fórmula tanto para determinar o $\mathrm{x}_{\mathrm{v}}$ e o $\mathrm{y}_{\mathrm{v}}$; apenas 5 deles, disseram que tentaram substituir o valor do $\mathrm{x}_{\mathrm{V}}$ na expressão dada, porém, errando o cálculo do $\mathrm{x}_{\mathrm{V}} \mathrm{e}$ substituindo na função encontraram valores absurdos do $\mathrm{y}_{\mathrm{v}}$.

No item d) onde o gráfico intercepta o eixo 0y (da ordenada) e as coordenadas do ponto, o fator que influenciou os erros foi que ao fazer o registro da coordenada do ponto, eles conseguiam dar o valor de $\mathrm{y}$, mas a dúvida ficou quanto ao valor de $\mathrm{x}$.

No quesito para fazer o esboço do gráfico, apenas 24 (46,15\%) acertaram, demonstrando a dificuldade dos alunos em valer-se dos itens (b, c, d) para realizar o registro gráfico, ou seja, converter um registro algébrico num registro gráfico. Os que acertaram, disseram que associaram a ideia da imagem do rosto de uma pessoa.

A maioria sem a disponibilização do gráfico, não conseguiu visualizar e definir o valor máximo ou mínimo (14 acertos - 26,92\%). A problemática maior dos alunos foi para definir o conjunto da variação no eixo y (a imagem) da função, com apenas 7 acertos (13,46 \%); o fator limitador dos alunos, acorreu por não terem a visão bidimensional envolvida pelos eixos ' $\mathrm{x}$ ' $\mathrm{e}$ ' $y$ '. Ressaltasse que abstrair a ideia dos sinais ligando o sentido dos eixos (quando tende para o infinito) e as regiões do plano cartesiano continua sendo o primeiro obstáculo. O segundo obstáculo se concentrou na significação operatória vinculada ao significante e que comanda o tratamento, ou seja, “associar o sinal ‘+' com o símbolo de desigualdade '>0' e o sinal '-' com o símbolo '<0' isso, para os alunos, não ocorre de forma natural e espontânea”.

Sobre o item (i) - verificar se os pontos $\mathrm{P}_{1}(-1 ; 10), \mathrm{P}_{2}(2 ;-5)$ e $\mathrm{P}_{3}(0 ; 4)$ pertencem ou não pertencem a função $\mathrm{f}(\mathrm{x})$, apenas 2 alunos $(3,85 \%)$ analisaram corretamente. Os outros relataram aos pesquisadores não sabiam o que fazer e/ou após substituir o valor de ' $\mathrm{x}$ ' na expressão erraram ao fazer o cálculo numérico. Verifica-se neste item a falta do domínio nas operações básicas como potenciação e regra de sinais.

Quanto ao item (j) - 'estudo dos sinais', foi exposto pelos estudantes, a dificuldade para relacionar o eixo x com o eixo y. Os pesquisadores concluem que a dúvida maior paira na ação 
para determinar o que deve ser projetado no eixo y fazendo uma correspondência dos sinais com os símbolos de desigualdade para então emitir a resposta da situação. O valor do 'eixo x' é o marco de referência para análise do sinal da função que representa o gráfico. Para os valores maiores que a raiz (valor que o gráfico corta o eixo $\mathrm{x}$ ) os valores de y são '+', ou seja, 'y >0' desde que a função seja crescente. E, para os valores menores que a raiz da função os valores de y são '-', ou seja, 'y<0'.

\section{Considerações Finais}

A matemática sendo constituída por regras e convenções ditas universais, ganha significado pelos problemas provenientes envolvidos com aplicações de tais regras, e se constroem pela ação dos homens. O que se diferencia nas práticas escolares são os métodos e os usos que se faz dele, de acordo com as opções epistemológicas e pedagógicas que se escolhe. Isso nos permite acreditar que as verdades matemáticas não estão prontas e acabadas e que não se descobre somente pela razão ou pelos nossos sentidos.

Neste trabalho, ficou evidente a dificuldade que os alunos têm para efetuar o tratamento e converter registros na linguagem natural, algébrica e gráfica. O que acontece, na verdade, é que a compreensão dos alunos fica limitada à forma de representação que eles conhecem e que sabem operar. Citando como exemplo, o da significação operatória vinculada ao significante e que comanda o tratamento, ou seja, associar o sinal '+' com o símbolo de desigualdade ' $>0$ ' e o sinal '-' com o símbolo ‘<0'; isso, para os alunos, não ocorre de forma natural e espontânea. Também, não esquecendo das operações básicas vistas desde o ensino fundamental e que eles apresentam déficit no seu uso.

Constata-se que o conhecimento abstrato vai ganhando significado com o seu uso, do particular ao geral, não bastando apenas ao professor ter domínio do conteúdo e uma boa retórica. É essencial que ele tenha aguçado senso para perceber onde pairam as principais limitações dos alunos no que diz respeito à compreensão dos registros apresentados, apontando procedimentos e técnicas para que eles alcancem o conhecimento pleno deste conteúdo, podendo até realizar aplicações ligadas com o seu cotidiano. Tem-se que considerar as tentativas e erros de alguns alunos no desenvolvimento do pensamento, considerando os espaços de tempo disponibilizado para perguntas e esclarecimento de possíveis dúvidas.

Conclui-se, afirmando que não bastam apenas atividades bem elaboradas, sequências de ensino bem estruturadas para se obter acesso ao saber. Elas por si mesmas, não garantem o 
processo de aprendizagem da matemática ao jogo de trânsito e conversões de registros de representação. Essas operações são importantes, mas devem ser consideradas em concordância com outros componentes da aprendizagem, tais como a natureza das tarefas escolares, aspectos envolvendo a aprendizagem da matemática, condições socioeconômicas dos alunos, dentre outros.

\section{Referências}

BRASIL. Ministério da Educação. Diretrizes Curriculares Nacionais para a formação de Professores da Educação Básica, em nível superior, curso de licenciatura, de graduação plena. Brasília: MEC, 2001. (Parecer CNP/CP 009/2001, aprovado em 08/05/2001).

COLOMBO, J. A. A. Representações semióticas no ensino: contribuições para reflexões acerca dos currículos de matemática escolar. 2008. 232 f. Tese (Doutorado em Educação Científica e Tecnológica) - Centro de Educação, Ciências Físicas, Biológicas e Matemáticas, Universidade Federal de Santa Catarina, Florianópolis, 2008.

FONT, V.; GODINO, J. D.; D'AMORE, B. Enfoque ontosemiótico de las representaciones em Educación Matemática. Disponível em: <http://www.urg.es/local/jgodino >. Acesso em: 23 set. 2015.

DUVAL, R. Registres de représentation sémiotique et fonctionnement cognitif de lapensée. In: DIDACTIQUE ET DE SCIENCES COGNITIVES, 1993, Strasbourg. Annales... Strasbourg: ULPIREM, 1993. v. 5, p. 37-65.

\section{. Sémiosis et Pensée Humaine - Registres sémiotiques et apprentissages intellectuals.}

Berne, Peter Lang, 1995.

Semiosis y pensamiento humano: registros semióticos y aprendizajes intelectuales. Traducción de Myriam Veja Restrepo. 2. ed. Santiago de Cali: Universidad del Valle, 2004.

Registros de representação semiótica e funcionamento cognitivo do pensamento. Tradução de Méricles Thadeu Moretti. REVEMAT, Florianópolis, v. 7, n. 2, p. 266-297, 2012. Disponível em: $<$ http://www.periodicos.ufsc.br/index.php/revemat/article/view/1981-1322.2012v7n2p266/23465>. Acesso em: 22 jan. 2016.

MORETTI, M. T. O papel dos registros de representação na aprendizagem de matemática. Contrapontos: Revista de Educação da Universidade do Vale do Itajaí, Itajaí, n. 6, p. 343-362, set./dez. 2002.

SAUSSURE, F. de. Curso de Linguística Geral. Tradução Antônio Chelini et al. 25. ed. São Paulo: Cultrix, 1996.

THIEL, A. A. Práticas matemáticas no plano cartesiano: um estudo da coordenação de registros de representação. 2013. 241 f. Tese (Doutorado em Educação Científica e Tecnológica) - Centro de Educação, Ciências Físicas, Biológicas e Matemáticas, Universidade Federal de Santa Catarina, Florianópolis, 2013.

WITTGENSTEIN, L. Investigaciones filosóficas. Barcelona: Crítica, 1953. 